\title{
Роль карбонатных расплавов в формировании мантийного источника санукитоидов
}

\author{
Егорова Ю.С. \\ ИГГД РАН, Санкт-Петербург, axoxyх2014@gmail.com
}

\begin{abstract}
Аннотация. Санукитоиды - архейские высоко-Mg Ba-Sr-гранитоиды и связанные с ними ультрамафитмафиты являются первым значительным проявлением мантийного магматизма повышенной щелочности в истории Земли. Обогащение LREE, Ba, Sr, K, P ранних мафит-ультрамафитовых фаз санукитоидных интрузий наряду с мантийными изотопными характеристиками указывает на то, что их источником были метасоматизированные породы мантии. В данной работе впервые предложена модель, в которой агентом метасоматоза являются ювенильные карбонатные расплавы, образующиеся в субконтинентальной литосферной мантии в равновесии с $\mathrm{Amp} \pm \mathrm{Phl} \pm \mathrm{Gnt}$ - перидотитом при $\mathrm{P}=21-31$ кбар и $\mathrm{T}=930-1080{ }^{\circ} \mathrm{C}$ в окислительных условиях (f $\left.\mathrm{O}_{2} \mathrm{QFM}\right)$. Декарбонизация этих расплавов при подъеме выше 60-65 км (P = 2 ГПа) приводит к формированию обогащенных LREE, LILE и Р верлитов. Частичное плавление этих пород могло произвести расплавы, отвечающие по составу примитивным санукитоидам.
\end{abstract}

Ключевые слова: санукитоиды, неоархей, метасоматоз мантии, Карельская провинция, Фенноскандинавский щит.

\section{The role of carbonate-rich melts in formation of the mantle sanukitoid source}

\section{Egorova Yu.S.}

IPPG RAS, St. Petersburg, axoxyx2014@gmail.com

\begin{abstract}
Sanukitoids are Archean high-Mg Ba-Sr granitoids, and associated ultramafic-mafic rocks are the first significant evidence of mantle subalkaline magmatism in the Earth's history. The enriched in LREE, Ba, Sr, K, P of the early mafic-ultramafic phases of the sanucitoid intrusions, along with the mantle isotope signatures, indicates that it occurred from metasomatized mantle rocks. In this paper, for the first time, a model is proposed, in which metasomatic agents are juvenile carbonate melts formed in the subcontinental lithospheric mantle in equilibrium with Amp $\pm \mathrm{Phl} \pm \mathrm{Gnt}$ - peridotite at $\mathrm{P}=21-31 \mathrm{kbar}$ and $\mathrm{T}=930-1080^{\circ} \mathrm{C}$ under oxidizing conditions $\left(\mathrm{f}_{\mathrm{O} 2} \sim \mathrm{QFM}\right)$. The decarbonization of these melts above $60-65 \mathrm{~km}(\mathrm{P}=2 \mathrm{GPa})$ leads to the formation of enriched in LREE, LILE, and P wehrlites. Partial melting of these rocks could produce melts corresponding in composition to primitive sanukitoids.
\end{abstract}

Keywords: sanukitoids, Neoarchean, mantle metasomatism, Karelian province, Fennoscandian Shield.

\section{Введение}

На всех архейских кратонах становление санукитоидных интрузий произошло на границе мезо-неоархея в узком интервале времени после формирования, деформации и метаморфизма основного объема коры, слагающей гранит-зеленокаменные области, и предшествовало внедрению К-гранитов и щелочных пород на завершающих этапах кратонизации. Из этого следует, что их формирование связано с закономерным этапом эволюции континентальной литосферы. Существование аналогов архейских санукитоидов - высоко-Mg Ba-Sr-гранитоидов и связанных с ними ультрамафитмафитов в фанерозое (Fowler et al., 2008; Choi et al., 2009 и др.), свидетельствует о том, что такие условия не являлись уникальными только для архея, как предполагалось, например, в работе (Martin et al., 2009). Высокая магнезиальность санукитоидов наряду с обогащением LREE, Ba, Sr, P и щелочами объясняется происхождением первичных санукитоидных расплавов из метасоматизированного мантийного источника (Shirey, Hanson, 1984; Lobach-Zhuchenko et al., 2005, и др). При этом состав агентов и механизмы метасоматоза мантии остаются дискуссионными. Это, в частности, связано с широким разнообразием составов пород, слагающих санукитоидные комплексы.

Анализ геохимических и изотопных данных для санукитоидов Карельской провинции (более 20 интрузий) позволил установить, что мантийные изотопные характеристики, как правило, со- 
храняют санукитоиды умереннощелочного ряда, наиболее обогащенные $L R E E, B a, S r, K, P$ (Егорова, 2014). Такие санукитоиды входят в состав массивов Панозеро, Эльмус, Хижъярви, Шаравалампи и др. При внедрении в кору санукитоидные расплавы в разной степени претерпели контаминацию, что изменило их состав и первичные изотопные характеристики в сторону таковых во вмещающих ТТГ породах (Егорова, 2014 и др.). Поэтому дальнейшие рассуждения о составе и условиях формирования метасоматизированного мантийного источника основываются на составе ранних фаз санукитоидных интрузий Карельской провинции, сохраняющих мантийные изотопные характеристики.

\section{Краткаягеохимическая изотопная характеристика примитивныхсанукитоидов}

По химическому составу они варьируют от ультрабазитов с $37 \% \mathrm{SiO}_{2}$ до монцодиоритов c $57 \% \mathrm{SiO}_{2}, \mathrm{mg} \#=0.80-0.54, \mathrm{MgO}=17-6 \%, \mathrm{Cr}=50-500 \mathrm{ppm}, \mathrm{Al}_{2} \mathrm{O}_{3}=7-15.5, \mathrm{~K}_{2} \mathrm{O}=1-4.2 \%$, $\mathrm{Sr}$ до 2000 ppm, Ва до 2500 ppm, $\mathrm{P}_{2} \mathrm{O}_{5}$ до $2.5 \%$, Се до $200 \mathrm{ppm}, \mathrm{Sm}$ до $20 \mathrm{ppm}$ и $\mathrm{La}_{\mathrm{N}} / \mathrm{Yb}_{\mathrm{N}}=10-30$ при $\mathrm{Yb} \sim 2$ ppm. Концентрации LREE снижаются по мере уменьшения содержания $\mathrm{SiO}_{2}$ (рис. 1a). Начальные изотопные отношения ${ }^{238} \mathrm{U} /{ }^{204} \mathrm{~Pb}(2.73$ млрд. лет $)=9 \pm 0.2, \varepsilon_{\mathrm{Nd}}(2.73$ млрд. лет $)=+1.6 \pm 0.5$ и изотопный состав углерода карбонатов $\left(\delta^{13} \mathrm{C}=-6 \pm 2 \%\right.$ отвечают мантийным значениям (Егорова, 2014).

\section{Формирование метасоматизированного мантийного источника санукитоидов}

Формирование метасоматизированного мантийного источника санукитоидов изначально связывалось с взаимодействием отделившихся от слэба флюидов/расплавов с мантийным перидотитом в зоне субдукции (Stern, Hanson, 1991; Самсонов и др., 2004; Martin et al., 2009, и др.). Экспериментальные работы (Rapp et al., 2010) и численное моделирование условий формирования и плавления источника санукитоидов (Самсонов и др., 2004; Oliveira et al., 2010; Semprich et al., 2015) с некоторыми допущениями удовлетворительно объясняют получение санукитоидов гранитоидного состава. Однако расчеты для менее дифференцированных санукитоидов провинции Сьюпериop (Semprich et al., 2015) показали необходимость привлечения дополнительного вещества, например, добавления в мантийный источник 5 \% карбонатитов. С другой стороны, если источником $\mathrm{K}, \mathrm{LREE}, \mathrm{P}, \mathrm{Ba}$ и $\mathrm{Sr}$ являлись породы субдуцирующей коры, то должна наблюдаться положительная корреляция между их концентрацией и долей коровой компоненты в изотопном составе $\mathrm{Nd}, \mathrm{Pb}$ и $\mathrm{Hf}$. Тем не менее, она отсутствует (Heilimo et al., 2010); наоборот, близкие к мантийным значения величин $\varepsilon_{\mathrm{Nd}}(\mathrm{t}), \mu(\mathrm{t})\left({ }^{238} \mathrm{U} / 204 \mathrm{~Pb}\right)$ характерны для санукитоидов, имеющих высокую степень обогащения некогерентными элементами (Егорова, Лобиков, 2013; Егорова, 2014). Поэтому привнос в источник $\mathrm{K}, \mathrm{Ba}$ и Sr был объяснен подъемом астеносферного вещества (Heilimo et al., 2010 и др.). На связь метасоматоза мантии с мантийными флюидами/расплавами также указывает изотопный состав углерода карбонатов Эльмусского и Панозерского массивов (Лохов и др., 2008) и близкого санукитоидам по возрасту и составу карбонатитового массива Ликаманникко в Финляндии (Mikkola et al., 2011).

Экспериментальные данные последних десятилетий позволяют предполагать, что в астеносфере за счет содержания $\mathrm{H}_{2} \mathrm{O}$ до 200 г/т в дефектах структуры нормативно безводных минералов между дегидратационным и сухим солидусом (заштрихованная область на рис. 1г) и интервале глубин 250-90 км должны зарождаться малые фракции расплавов, обогащенных несовместимыми элементами, особенно LREE, Ba, Sr, K, P, С и H (Green, 2015). Миграция этих расплавов вдоль геотермы обуславливает обеднение нижней и обогащение верхней астеносферы, обеспечивая ее гетерогенность (Green, 2015). В окислительных условиях $\left(f \mathrm{O}_{2} \sim \mathrm{IW}+3-4 \log\right.$ ед., величина, близкая к таковой в QFM буфере) и диапазоне температур 930-1200 ${ }^{\circ} \mathrm{C}$ подъем астеносферного вещества выше 90-95 км (30-32 кБар) приводит к реакции с образованием паргасита и небольшой фракции равновесного с ним карбонатного расплава (Wallace, Green, 1988). Этот расплав будет обогащен LREE, $\mathrm{Ba}, \mathrm{Sr}, \mathrm{P}$ и обеднен HFSE и HREE (рис. 1в). Содержание и соотношение щелочей будет определяться концентрацией K и Na в системе (Sweeney, 1994; Martin et al., 2013). Большая подвижность карбонатного расплава должна обеспечивать его подъем из области генерации до уровня декарбонизации ( 60-65 км (21 кбар), рис. 1 г) согласно реакции: $\mathrm{Ol}+\mathrm{OPx}+\mathrm{L}_{\mathrm{Carb}}=\mathrm{Ol}+\mathrm{CPx}+\mathrm{CO}_{2}$, что приве- 

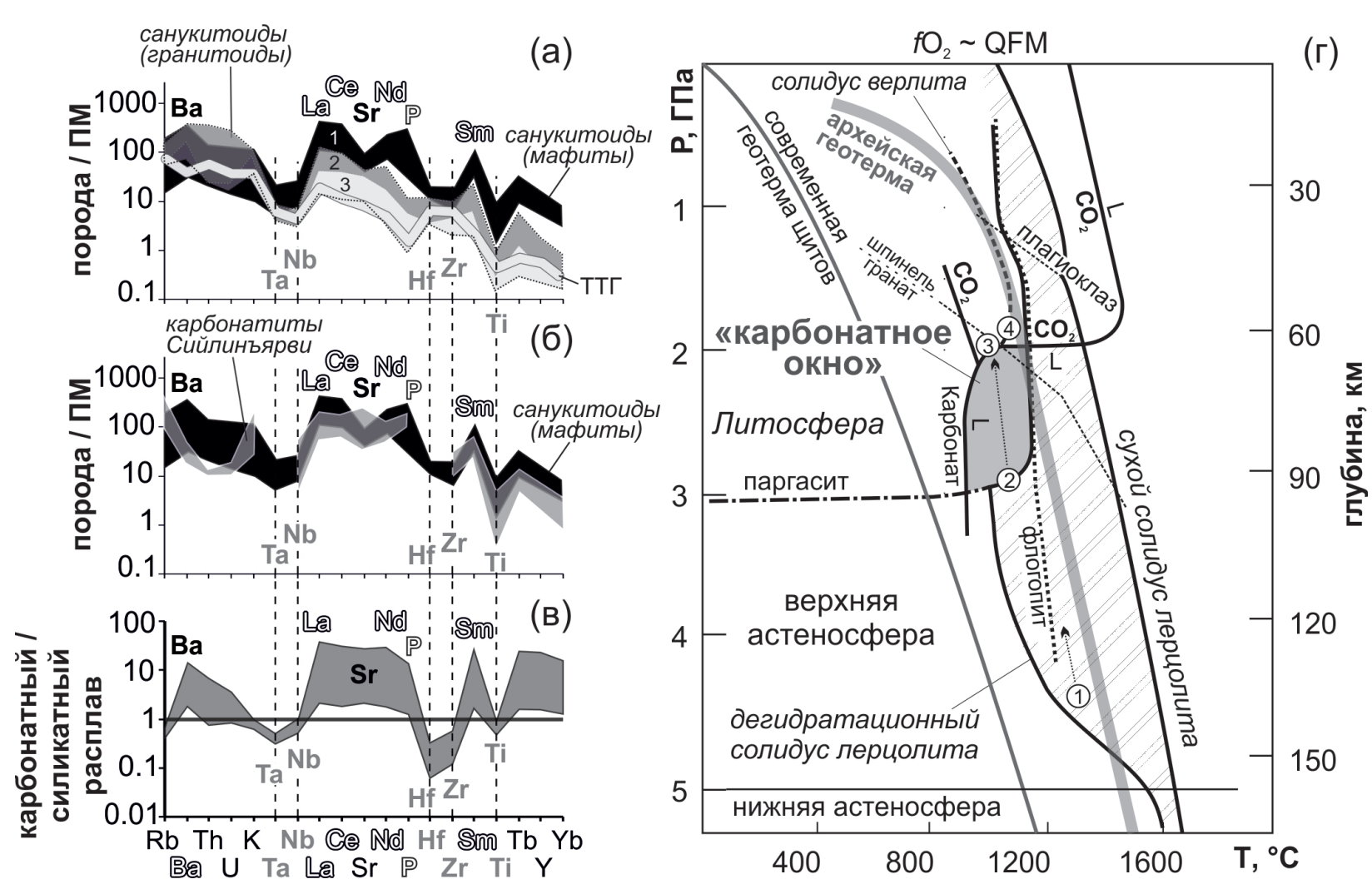

Рис. 1. (а-б) - спектры распределения редких и редкоземельных элементов, нормированные на примитивную мантию по (Sun, McDonough, 1989), для средних составов ранних магматических фаз ультраосновного и основного состава (1) санукитоидных интрузий Карелии: (а) - в сравнении с санукитоидами среднего и кислого состава умереннощелочного (2) и нормальнощелочного ряда (3), а также со средним составом архейских ТТГ Фенноскандинавского щита (по Чекулаеву и Глебовицкому, 2017); (б) - в сравнении с карбонатитами Сийлинъярви (по O’Brien et al., 2015); (в) - распределение редких элементов между карбонатным и силикатным расплавом в присутствии воды при $\mathrm{P}=10-30$ кбар и $\mathrm{T}=1050-1260^{\circ} \mathrm{C}$ (Martin et al., 2013). (г) - $\mathrm{PT}$ диаграмма, определяющая условия возникновения мантийных карбонатных расплавов в равновесии с паргаситом в условиях внутриплитного режима при $\mathrm{P}=2-3.2$ ГПа: $0.3 \mathrm{wt} \% \mathrm{H}_{2} \mathrm{O}$ и $0.5-2.5 \mathrm{wt} \% \mathrm{CO}_{2}$ по (Green, 2015). Солидус верлита и линии фазового перехода для карбонатной фазы даны по (Lee, Wyllie, 2000). Линия устойчивости флогопита дана по (Mengel, Green, 1989), архейская геотерма по (Santosh et al., 2010).

Fig. 1. (a-б) - average primitive mantle normalized (Sun, McDonough, 1989) trace and REE patterns for the early ultrabasic and basic magmatic phases (1) of the Karelia sanukitoid intrusions: (a) - in comparison with felsic sanukitoids of subalkaline series (2) and calk-alkaline series (3) and with average Archean TTG of the Fennoscandian Shield after (Chekulaev, Glebovitsky, 2017); (б) - with the Siilinjärvi carbonatites (O'Brien et al., 2015); (в) - distribution of rare elements between carbonate and silicate melt under water-saturated conditions at $\mathrm{P}=10-30 \mathrm{kbar}$ and $\mathrm{T}=1050-1260^{\circ} \mathrm{C}$ (Martin et al., 2013). (г) - PT diagram determining the conditions for the appearance of mantle carbonate melts in equilibrium with pargasite under the intraplate conditions at $\mathrm{P}=2-3.2 \mathrm{GPa} ; 0.3 \mathrm{wt} . \% \mathrm{H}_{2} \mathrm{O}$ and $0.5-2.5 \mathrm{wt} . \% \mathrm{CO}_{2}$ (Green, 2015). Solidus wehrlite and carbonate phase transition are given after (Lee, Wyllie, 2000), the phlogopite stability line after (Mengel, Green, 1989) and Archean geotherm after (Santosh et al., 2010).

дет к формированию метасоматизированных пород мантии - верлитов, содержащих $\mathrm{Ap} \pm \mathrm{Amp} \pm \mathrm{Phl}$ (Green, Wallace, 1988; Sweeney, 1994; Lee, Wyllie, 2000). При дополнительном притоке тепла, участки верлитовой мантии будут плавиться в первую очередь (рис. 1 г), с образованием обогащенных LREE, $\mathrm{Ba}, \mathrm{Sr}, \mathrm{P}$ и щелочами расплавов. В случаях, когда существуют благоприятные условия для быстрого выведения карбонатных расплавов на поверхность, согласно модели (Green, Wallace, 1988), будут формироваться щелочные карбонатитовые комплексы, такие, как, например, Сийлинъярви в Западной Карелии (2.62 млрд. лет). 
Спектр распределения редких элементов для средних составов ранних ультрамафитмафитовых фаз санукитоидов имеет большое сходство со спектром неоахейских мантийных карбонатитов Сийлинъярви (рис. 1 б) и хорошо согласуется с экспериментально установленным (Martin et al., 2013) распределением редких элементов в карбонатный расплав при $\mathrm{T}=1050-1260^{\circ} \mathrm{C}$, $\mathrm{P}=1-3$ ГПа в присутствии $\mathrm{H}_{2} \mathrm{O}$ (рис. 1 в). Также карбонатиты Сийлинъярви имеют сходный с примитивными санукитоидами изотопный состав неодима $\left(\varepsilon_{\mathrm{Nd}}(2.61)=+2.3\right)$ и изотопный состав $\mathrm{C}$ и $\mathrm{O}$ $\left(\delta^{13} \mathrm{C}=-3.7 \%\right.$, $\delta^{18} \mathrm{O}=7.4 \%$ ) (Tichomirova et al., 2006). Вывод о возможном участии карбонатных расплавов в формировании обогащенного мантийного источника санукитоидов подтверждается результатами численного моделирования (Semprich et al., 2015).

\section{РТ режим и окислительно-восстановительные условия в архейской мантии}

Окислительные условия ( $f_{\text {O2 }} \sim$ как в QFM буфере), необходимые для образования первичных карбонатных расплавов в равновесии с паргаситом, реализуются в субконтинентальной верхней мантии под утолщенной зрелой корой континентов (Green, Wallace, 1988). Это согласуется со становлением санукитоидов на всех древних кратонах после формирования основного объема континентальной коры в посттектонических условиях.

Охлаждение литосферы на глубине 60-90 км до температур около $1000^{\circ} \mathrm{C}$ является вторым необходимым условием, так как архейская геотерма проходит правее карбонатного окна, что делает невозможным появление карбонатных расплавов в равновесии с паргаситом, а также существования флогопита и амфибола на глубинах больше 65 км (рис. 1 г). Вероятно, это и происходило на рубеже мезо- и неоархея на нашей планете и объясняет отсутствие похожих на санукитоиды пород в более ранней истории Земли. Так как современная геотерма под зрелыми континентами лежит в области существенно более низких температур относительно карбонатного окна (рис. 1 г), фанерозойские аналоги санукитоидов (Ba-Sr габбро-гранитоидные комплексы) редки, хотя и описаны в ряде районов (Fowler et al., 2008; Choi et al., 2009, и др.). Происхождение последних связывается с астеносферным поднятием (оно обеспечивает приток тепла и некогерентных элементов (LREE, LILE, P, Н-C-O) в верхние слои мантии) в результате деламинации (отслоения) нижних слоев литосферы (Choi et al., 2009 и др.) или обрыва субдуцирующего слэба (Fowler et al., 2008, и др.) на постколлизионной стадии формирования орогенов. Вполне возможно, что похожие тектонические процессы предшествовали формированию архейских санукитоидов, так как их становление на всех кратонах происходило на завершающих стадиях консолидации коры.

\section{Общая петрологическая модель, объясняющая геохимические особенности мантийных санукитоидных расплавов}

Обогащение $\mathrm{Ba}, \mathrm{Sr}, \mathrm{P}, \mathrm{LREE}$ и щелочами, обеднение HFSE, HREE, Y и характерный профиль спектра распределения редких элементов примитивных санукитоидов формируются в результате нескольких этапов фракционирования: (1) - образование малых фракций расплавов в астеносфеpe, обогащенных несовместимыми элементами (LREE, $\mathrm{Ba}, \mathrm{Sr}, \mathrm{K}, \mathrm{Na}, \mathrm{P}, \mathrm{C}$ и H) и их подъем, (2) - на границе 90-95 км (30-32 кБар) при $930^{\circ} \mathrm{C}<\mathrm{T}<1200^{\circ} \mathrm{C}$ и $\mathrm{fO}_{2} \sim \mathrm{IW}+3-4 \log$ ед. - реакция с образованием паргасита и равновесного с ним карбонатного расплава $\rightarrow$ фракционирование редких элементов согласно их коэффициентам распределения: обогащение карбонатного расплава LREE, Ba, $\mathrm{Sr}, \mathrm{K}, \mathrm{Na}$ и P, обеднение HFSE и HREE, (3) - подъем карбонатного расплава до 60-65 км $\rightarrow$ декарбонизация и метасоматическая реакция с вмещающим перидотитом $\rightarrow$ образование обогащенного верлита, наследующего спектр распределения редких элементов от карбонатного расплава; (4) - дополнительный приток тепла $\rightarrow$ плавление обогащенного верлита с образованием первичных санукитоидных расплавов (рис. 1 г).

\section{Выводы}

Специфика химического состава примитивных санукитоидов хорошо согласуется с экспериментально установленным (Martin et al., 2013) распределением редких элементов в карбонатный расплав при $\mathrm{T}=1050-1260^{\circ} \mathrm{C}, \mathrm{P}=1-3$ ГПа в присутствии $\mathrm{H}_{2} \mathrm{O}$. 
Карбонатные расплавы по данным экспериментов могут формироваться в субконтинентальной литосферной мантии в равновесии с $\mathrm{Amp} \pm \mathrm{Phl} \pm \mathrm{Gnt}$ - перидотитом в окислительных условиях ( $\mathrm{f}_{\mathrm{O} 2} \sim$ как в QFM буфере) при $\mathrm{P}=21-31$ кбар и $\mathrm{T}=930-1080{ }^{\circ} \mathrm{C}$ (Wallace, Green, 1988; Sweeney, 1994). В конце архея такие условия могли быть реализованы за счет увеличение мощности континентальной коры и постепенного охлаждения литосферы кратонов. В фанерозойское время для создания аналогичных условий, наоборот, требовался дополнительный приток тепла (рис. 1 г).

Формирование метасоматизированных пород мантии - обогащенных LREE, LILE и P верлитов, - возможно в результате декарбонизации карбонатных расплавов на границе 60-65 км (P 2 ГПа), приводящей к реакции с вмещающими породами: $\mathrm{Ol}+\mathrm{OPx}+\mathrm{L}_{\text {Carb }}=\mathrm{Ol}+\mathrm{CPx}+\mathrm{CO}_{2} \pm$ $\mathrm{Ap} \pm \mathrm{Amp} \pm \mathrm{Phl}$ (Green, Wallace, 1988; Sweeney, 1994; Lee, Wyllie, 2000). Частичное плавление этих пород может произвести расплавы, отвечающие по составу примитивным санукитоидам.

Обогащение и плавление мантийного источника были близки во времени, о чем свидетельствуют мантийные изотопные характеристики примитивных санукитоидов. Эти процессы происходили в начале неоархея почти синхронно на всей территории Карельского кратона, так как одновозрастные ( $2.74 \pm 0.1$ млрд. лет) санукитоиды с мантийными изотопными характеристиками присутствуют в разновозрастных доменах (Ликаманникко - Западно-Карельский домен, Панозеро и др. - Центрально-Карельский домен, Эльмус - Водлозерский домен).

Работа выполнена в рамках темы НИР ИГГД РАН № 0153-2019-0001.

\section{Литература}

1. Егорова Ю.С., Лобиков А.Ф. Изотопный состав свинца и неодима санукитоидов Карелии как свидетельство их гетерогенной природы // Доклады АН. 2013. Т. 453. № 2. С. 196-200. DOI: 10.7868/ S0869565213320170.

2. Егорова Ю.С. Санукитоиды Фенно-Карельской провинции Балтийского щита: геология, состав, источники. Автореф. канд. дис-ии. С.-Петербург. 2014. 20 с.

3. Лохов К.И., Егорова Ю.С., Лобач-Жученко С.Б. и др. Изотопный состав углерода и кислорода карбонатов из архейских санукитоидных интрузий Карелии: к проблеме мантийного флюида // Региональная геология и металлогения. 2008. № 36. С. 28-39.

4. Самсонов А.В., Бибикова Е.В., Ларионова Ю.О. и др. Магнезиальные гранитоиды (санукитоиды) Костомукшского района, Западная Карелия: петрология, геохронология и тектонические условия становления // Петрология. 2004. Т. 12. № 5. С. 495-529.

5. Чекулаев В.П., Глебовицкий В.А. О среднем составе ТТГ (тоналит-трондьемит-гранодиоритовой) ассоциации: возможности использования // Доклады АН. 2017. Т. 472. № 2. С. 192-196. DOI: 10.7868/ S0869565217020177.

6. Choi S.-G., Rajesh V.J., Seo J. et al. Petrology, geochronology and tectonic implications of Mesozoic high Ba-Sr granites in the Haemi area, Hongseong Belt, South Korea // Island Arc. 2009. V. 18. P. 266-281. DOI:10.1111/ j.1440-1738.2008.00622.x.

7. Fowler M.B., Kocks H., Darbyshire D.P.F., Greenwood P.B. Petrogenesis of high Ba-Sr plutons from the Northern Highlands Terrane of the British Caledonian Province // Lithos. 2008. V. 105. P. 129-148. DOI: 10.1016/j. lithos.2008.03.003.

8. Green D.H., Wallace M.E. Mantle metasomatism by ephemeral carbonatite melts // Nature. 1988. V. 336. P. 459-462.

9. Green D.H. Experimental petrology of peridotites, including effects of water and carbon on melting in the Earth's upper mantle // Phys. Chem. Minerals. 2015. V. 42. P. 95-122. DOI: 10.1007/s00269-014-0729-2.

10. Heilimo E., Halla J., Hölttä P. Discrimination and origin of the sanukitoid series: Geochemical constraints from the Neoarchean western Karelian Province (Finland) // Lithos. 2010. V. 115. P. 27-39. DOI: 10.1016/j. lithos.2009.11.001

11. Lee W.J., Wyllie P.J. The system $\mathrm{CaO}-\mathrm{MgO}-\mathrm{SiO}_{2}-\mathrm{CO}_{2}$ at $1 \mathrm{GPa}$, metasomatic wehrlites, and primary carbonatite magmas // Contr. to Mineral. and Petrol. 2000. V. 138. P. 214-228.

12. Lobach-Zhuchenko S.B., Rollinson H.R., Chekulaev V.P., et al. The Archaean sanukitoid series of the Baltic Shield: geological setting, geochemical characteristics and implications for their origin // Lithos. 2005. V. 79. P. 107-128. DOI: 10.1016/j.lithos.2004.04.052.

13. Mengel K., Green D.H. Stability of amphibole and phlogopite in metasomatized peridotite under water-saturated and water-undersaturated conditions // Fourth International Kimberlite Conference, Perth. Geol. Soc. Aust. Spec. Publ. 1989. V. 14. P. 571- 581. 
14. Martin H., Moyen J.F., Rapp R.P. The sanukitoid series: magmatism at the Archaean-Proterozoic transition // Earth and Environmental Science Transactions of the Royal Society of Edinburgh. 2009. V. 100. N. 1-2. P. 15-33. DOI: 10.1130/2010.2472(02).

15. Martin L.H.J, Schmid M.W, Mattsson H.B, Guenther D. Element Partitioning between Immiscible Carbonatite and Silicate Melts for Dry and H2O-bearing Systems at 1-3 GPa // J. Petrol. 2013. V. 54. № 11. P. 2301-2338. DOI:10.1093/petrology/egt048.

16. Mikkola P., Salminen P., Torppa A., Huhma H. The 2.74 Ga Likamännikkö complex in Suomussalmi, East Finland: lost between sanukitoids and truly alkaline rocks? // Lithos. 2011. V. 125. P. 716-728. DOI:10.1016/j. lithos.2011.04.002.

17. O’Brien H., Heilimo E., Heino P. The Archean Siilinjärvi Carbonatite Complex // Mineral Deposits of Finland. 2015. Chapter 4.3. P. 327-343.

18. Oliveira M.A., Dall'Agnol R., Scaillet B. Petrological Constraints on Crystallization Conditions of Mesoarchean Sanukitoid Rocks, Southeastern Amazonian Craton, Brazil // Journal of Petrology. 2010. V. 51. P. 2121-2148. DOI:10.1093/petrology/egq051.

19. Rapp R., Norman M., Laporte D. et al. Continent Formation in the Archean and Chemical Evolution of the Cratonic Lithosphere: Melt-Rock Reaction Experiments at 3-4 GPa and Petrogenesis of Archean Mg-Diorites (Sanukitoids) // Journal of Petrology. 2010. V. 51. P. 1237-1266. DOI:10.1093/petrology/egq017.

20. Santosh M., Maruyama Sh., Komiya T., Yamamoto Sh. Orogens in the evolving Earth: from surface continents to 'lost continents' at the core-mantle boundary // Geol. Soc. London. Spec. Publ. 2010. V. 338. P. 77-116. DOI: 10.1144/SP338.5.

21. Semprich J., Moreno J.A., Oliveira E.P. Phase equilibria and trace element modeling of Archean sanukitoid melts // Precambrian Research. 2015. V. 269. P. 122-138. DOI:10.1016/j.precamres.2015.08.004.

22. Stern R., Hanson G. Archean high-Mg granodiorite: a derivative of light rare earth element-enriched monzodiorite of mantle origin // J. Petrol. 1991. V. 32. №1. P. 201-238. DOI: 10.1093/petrology/32.1.201.

23. Sun S.S., McDonough W.F. Chemical and isotopic systematics of oceanic basalts; implications for mantle composition and processes // Geol. Soc., Special Publications. 1989. V. 42. P. 313-345.

24. Sweeney R.J. Carbonatite melt compositions in the Earth's mantle // Earth Planet. Sci. Lett. 1994. V. 128. P. 259-270. DOI:10.1016/0012-821x(94)90149-x.

25. Tichomirova M., Grosche G., Götze J. et al. The mineral isotope composition of two Precambrian carbonatite complexes from the Kola Alkaline Province-alteration versus primary magmatic signatures // Lithos. 2006. V. 91. P. 229-249. DOI:10.1016/j.lithos.2006.03.019.

26. Wallace M.E., Green D.H. An experimental determination of primary carbonatite magma composition // Nature. 1988. V. 335. P. 343-346. 